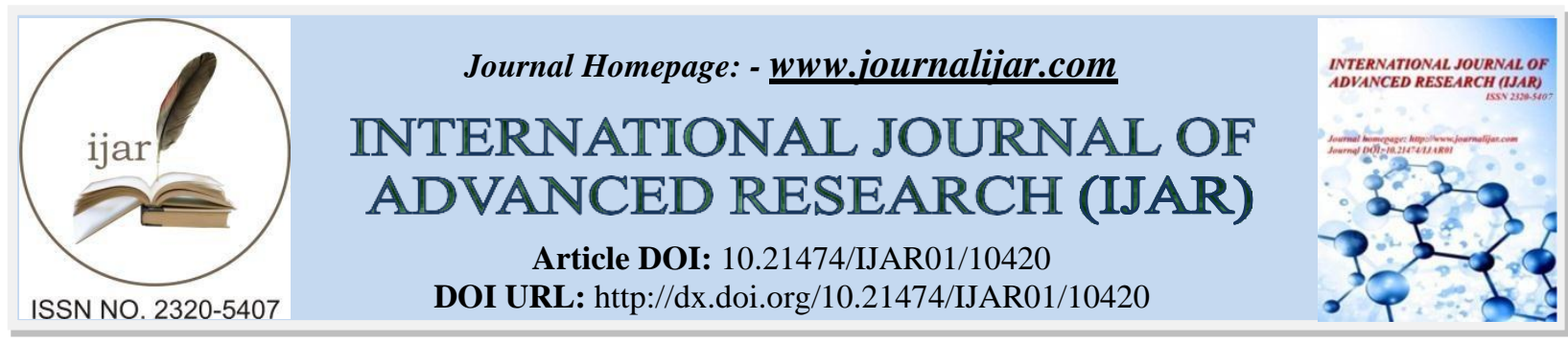

RESEARCH ARTICLE

\title{
VALGUS INTERTROCHANTERIC OSTEOTOMY FOR NON - UNION OF FEMORAL NECK USING THE DYNAMIC HIP SCREW
}

\author{
Issam Ait Hadj Sliman, Amine Abdelaoui, Mohamed Amine Benhima, Imad Abkari, Youssef Najeb and \\ Halim Saidi \\ Orthopaedic Trauma University Service, Hospital of Marrakech.
}

\section{Manuscript Info}

Manuscript History

Received: 30 November 2019

Final Accepted: 31 December 2019

Published: January 2020

\section{Key words:-}

Non Union Femoral, Neck, Intertrochanteric Osteotomy Dynamic Hip Screw

\begin{abstract}
The Non-union is a frequent complication of the femoral neck fracture. Its genesis implicates several factors in particular the age, the characteristics of the fracture, the state of the femoral head and the type of the treatment (absence ortherapeutic imperfection). Several techniques of femoral valgus osteotomy were described for the treatment of these non-union, our technique using the "dynamic hip screw" is an original therapeutic method which gives good performances. Our study concerns 09 cases of femoral neck non-union treated by valgus osteotomy at the university hospitalMohammed VI of Marrakech from January 2013 to August 2016.The averageage of our patients was 46 years. The valgus angle of the osteotomy was between $25^{\circ}$ and $40^{\circ}$ with an average of $29^{\circ}$. All our patients were healed with satisfying functional results. Indeed the type of fracture and his initial treatment also the type and the characteristic of the non-union doesn't influence the consolidation. Femoral head necrosis is a frightening complication which evolves on its own account and may occur at anytime. It is a significant factor for functional degradation and no cases have been noticed in our series. The quality of the results which we got, encourages us to suggest this treatment in all femoral neck nonunion cases among the young patients, if the head is supposed alive.
\end{abstract}

Copy Right, IJAR, 2020,. All rights reserved.

\section{Introduction:}

The Non-union of the femoral neck is considered as the major and most redoubted complication of femoral neck factures due to his high frequency and his often association with ischemic necrosis femoral head [1-2]. Yet there are few reports on the results of valgus intertrochanteric osteotomy in cases of femoral neck non-union [2]. The valgus intertrochanteric osteotomy is a conservatory technic belonging to the arsenal therapeutic of femoral neck nonunion[3]. The concept of valgus osteotomy was defined by Pauwels [4] in 1927, according to his findings showing that non-union of femoral neck was due to the high shear forces that increased with the vertical orientation of the fracture. The proposed biomechanical solution was to redirect these forces into compression forces via an angulation osteotomy and fixation with a dynamic hip screw. The purpose of our study is to show the particular technical aspects of our practice and evaluate the results.

Corresponding Author: Issam Ait Hadj Sliman

Address:- Orthopaedic Trauma University Service, Hospital of Marrakech. 


\section{Hypothesis:}

We hypothesized that the intertrochanteric osteotomy for femoral neck non-union using a dynamic hip screw is a technique which would allow excellent functional outcome compared to the others techniques of osteotomy, and these results were very satisfying.

\section{Patients and Methods:- \\ Patients:}

Our study is retrospective included 09 cases during 3 years from January 2013 to October 2016. The selection criteria of the patients in this present study has been as following: all the patients have undergone an intertrochanteric osteotomy for femoral neck non-union using a dynamic hip screw whatever the age, the type of the fracture and the initial treatment.

\section{Methods:-}

The follow up data includes epidemiologic, clinical and radiographic elements. The patient is installed in dorsal decubitus position on an orthopedic table under image intensification. We used a subtrochanteric Lateral approach (8 in $10 \mathrm{~cm}$ ). The proposed biomechanical solution was to redirect these forces into compression forces via an angulation osteotomy (60 degree relative to the perpendicular) and fixation with a dynamic hip screw [Fig 1,(a)].The first step is the insertion of cervical screw under image intensification, and then we realize a transverse intertrochanteric osteotomy perpendicular to the cervical screw, approximately 1 to $2 \mathrm{~cm}$ under the introduction point of the cervical screw, and that without excision of lateral wedge [Fig1,(b)]. The compression screw increase's the compressive forces around the non-union site, the introduction of the external corner into the medullary canal, by making a slight abduction of the femur, allows a good contact at the focus of the osteotomy and therefore a better consolidation [Fig 1,(c)]. The valgus angle of the osteotomy is between $25^{\circ}$ and $40^{\circ}$ with an average of $29^{\circ}$. Finally fixation of the plate (4 to 5 holes) allowing a stable mounting.

\section{Results:-}

\section{Epidemiological data:}

The average age of the patients of the intertrochanteric osteotomy was 46 years (range 37 - 60 years), the male to female ratio was 12,6. The initial fracture is caused by a fall for 6 cases and the right side was reached at 5 cases $(55,6 \%)$. The initial treatment of femoral neck fracture was surgical (screwing) for only 3 cases, the rest of our patients did not have any preliminary treatment.

\section{Clinical data:}

The oldest fracture of our series goes back to 14 months, whereas the most recent goes to 4 months with an average of 8 month. All the patients had consulted for pain of their hips (100\%), 33\% of them presente a partial fonctionnal disability and $44 \%$ had a shortening leg.

\section{Radiographical data:}

The resorption of the femoral neck was minimal with conservation of the neck length among 7 patients (77\%). The non-union is generally transcervical in $56 \%$ of our cases. The tight character of the non-union is prevailling of our series whatever his location. We did not observed any evident radiological sign of necrosis femoral head.

\section{Therapeutic result:}

The patients were followed for an average period of 4 years (range 3-6 years). The consolidation was obtained in all the patients of our series (100\%). The valgus angle of the osteotomy was between $25^{\circ}$ and $40^{\circ}$ with an average of $29^{\circ}$. The results obtained were satisfying: excellent (at $89 \%$ cases) according to the Merle d'Aubigné score.Some results of our osteotomy are presented in the figures[2, 3 and 4$]$.

\section{Discussion:-}

The frequency of the non-union femoral neck in the literature is reported to be between $10 \%$ and $30 \%[1,5,6,7]$. The male ascendancy would be due probably to the male predisposition in the accidents and violents falls. The nonunion femoral neck fracture of an active patient less than 65 years is generally treated by a preserving treatment, one of which, the valgus osteotomy with the purpose of protecting the femoral head [7,8,9]. The right predominance will probably due to hasard and this without any justification in litteratury studdies. The fastly taking care of the initial fracture has a great interest as it let avoide the occurrence of non-union and also femoral head necrosis. In fact, the 
deadline in the initial taking care is a promoting factor for the non-union and the necrosis femoral head [7,10]. In our context, the lack or the faillure of the treatment comes as the head list of the promoting factors of non-union, and we find in most of the series that more than $90 \%$ of cases were treated initialy by a percutaneous screw as the series of Hartford [2] or by screwing and DHS as the series of Byung-Woomin[11]. The diagnosis of the non-union can be confirmed just after the deadline of the femoral neck fracture estimed by 4 at 5 months. The head femoral necrosis is the most reported complication in most of the series. Others complications of the valgus osteotomy were reported in the literatury as the migration of the implant, the infection or secondary non-union (Retroverted position of the femoral head ). Pawels [4] was the first one to describe the concept using the valgus osteotomy to convert the shear forces to compressive forces at the non-union site, then several authors reported very well results for this technique $[2,9,12,13,14,15,16]$. Our series is only the 3rd in orthopaedic literature using valgus intertrochanteric osteotomy and fixation with a dynamic hip screw. Our results has similar as the others series reported by Harford [2] and Andrew [3] with a consolidation of all cases. The advantages of our technique are first the insertion of cervical screw and the use of the side plate that allow the manipulation of the proximal femoral fragment and increase the control of the rotation of the side plate during insertion. The drilling path of the cervical screw can be considered as an autograft bone of the fracture site. The compression screw increase's the compressive forces around the nonunion site [2,3]. And finally, the introduction of the external corner intramedullary allows a good contact at the focus of the osteotomy and therefore a better consolidation. The disadvantages of our technique are: the use of the cervical screw that increases the volume of the extracted bone during drilling wich can be a nonconsolidation factor, but this situation was found in none of our patients. The reduction of the cervical lever arm imposed by the valgus osteotomy engage some mechanical constraints that leads to a late osteoarthritis of the hip.

\section{Conclusion:-}

Our technique of osteotomy using the dynamic hip screw, which is different than the one described by Pawels is a conservative technique that is taking part of the therapeutic arsenal of the femoral neck non-union. It holds many advantages compared to the other techniques of osteotomy, and these results were very satisfying.

\section{Conflicts Of Interest:}

The authors confirm that there are no known conflicts of interest associated with this publication and there has been no significant financial support for this work that could have influenced its outcome.

\section{What is already known on this topic :}

1. The valgus intertrochanteric osteotomy is a conservatory technic belonging to the arsenal therapeutic of femoral neck non-union.

2. The concept of valgus osteotomy was defined initially by Pauwels.

3. Several techniques of femoral valgus osteotomy were described for the treatment of these non-union, our technique using the "dynamic hip screw" is an original therapeutic method which gives good performances.

\section{What this study adds:}

1. The advantages of our technique are first the insertion of cervical screw and the use of the side plate that allow the manipulation of the proximal femoral fragment and increase the control of the rotation of the side plate during insertion.

2. Also the drilling path of the cervical screw can be considered as an autograft bone of the fracture site. The compression screw increase's the compressive forces around the non-union site

3. And finally, the introduction of the external corner intramedullary allows a good contact at the focus of the osteotomy and therefore a better consolidation

Author's contributions:

All authors contributed to this work, and state that they have read and approved the final version of the manuscript

\section{References:-}

1. Zehi A, Bouguira F, Saadaoui M.H, Meherzi S, Karray M, Zouari T, Litaiem M,Douik.Ostéotomie de valgisation dans les pseudarthroses du col du fémur à propos de 41 cas. Revue Chir Ortho.2001;87(6):562-568.

2. Hartford JM, Patel A, Powell J.Intertrochantericosteotomyusing a dynamic hip screw for femoral neck nonunion.J Orthop Trauma. 2005; 19 (5):329-33. 
3. Andrew J,Schoenfeld, MD* and Gregory A,VrabecMD, FRCS.Valgus Osteotomy of the Proximal FemurwithSliding Hip Screw for the Treatment offemoral Neck Nonunions. The Technique. A case seriesand LiteratureReview.J Orthop Trauma. August 2006; 20(7):485-491.

4. Pauwels F. Biomechanics of the normal anddiseased hip.Berlin Springer-Verlag.1976;129-271.

5. Hui AC, Anderson GH, Choundry R.Internal fixation or hemiarthroplasty for undisplaced fractures of the femoral neck inoctogenarians. J Bone Joint Surg Br. 1994;76:891-894.

6. Lu-Yao GL, Keller RB, Littenberg B, et al. Outcomesafter displaced fractures of the femoral neck.

7. A metaanalysisof one hundred and six published reports. JBone Joint Surg Am. 1994;76:15-25.

8. MartiRk, Hans M, Schuller, Ernst LFB, Raaymakers.Intertrochanteric osteotomy for non-union of the femoralneck.JBone Joint SurgBr. 1989;71(B) :782-87.

9. Swiontkowski MF. Intracapsular fractures of the hip.Current Concept Review.J Bone joint Surg 1994;76(A) :129-38.

10. Ballmer FT, Ballmer PM, Baumgaertel F, et al.Pauwels osteotomy for non-unions of the femoral neck.Orthop clin North Am. 1990;21:759-67.

11. Asnis SE, Gould ES, Bansal M, Rizzo PF, Bullough PG.Megnetic resonance imaging of the hip after displaced femoral neck fractures. ClinOrthop.1994;298:191-98.

12. Byung-Woo Min, Ki-CheolBae, Chul-HyungKang,Kwang-Soon Song.Valgus intertrochanteric osteotomyfor non-union of femoral neck fracture Injury. 2006;37:786-90.

13. Gerundini M, Avai A, Taglioretti J. Total hipreplacement after intertrochanteric osteotomy. Int Orthop.1995;19(2):84-5.

14 Pidhorz L, Lahbabi S, Deburge A. Lespseudarthroses du col du fémur. Traitement parostéotomieintertrochantérienne.RevChirOrthop.1974;60:205-21.

15 Deburge A, Lahbabi S. Résultats des ostéotomiesintertrochantériennes dans le traitement des pseudarthroses du col du fémur.RevchirOrthop.1972;58:281-84.

16 Wu CC, Shih CH, Chen WJ, et al. Treatment offemoral neck non-union with a sliding compression screw.Comparison with and withoutsubtrochantericvalgusosteotomy. J Trauma.1999; 46:312-17.

17 Min BW1, Bae KC, Kang CH, Song KS, Kim SY, Won YY.Valgus intertrochanteric osteotomy for non-union of femoral neck fractureInjury. 2006 Aug;37(8):786-90. 


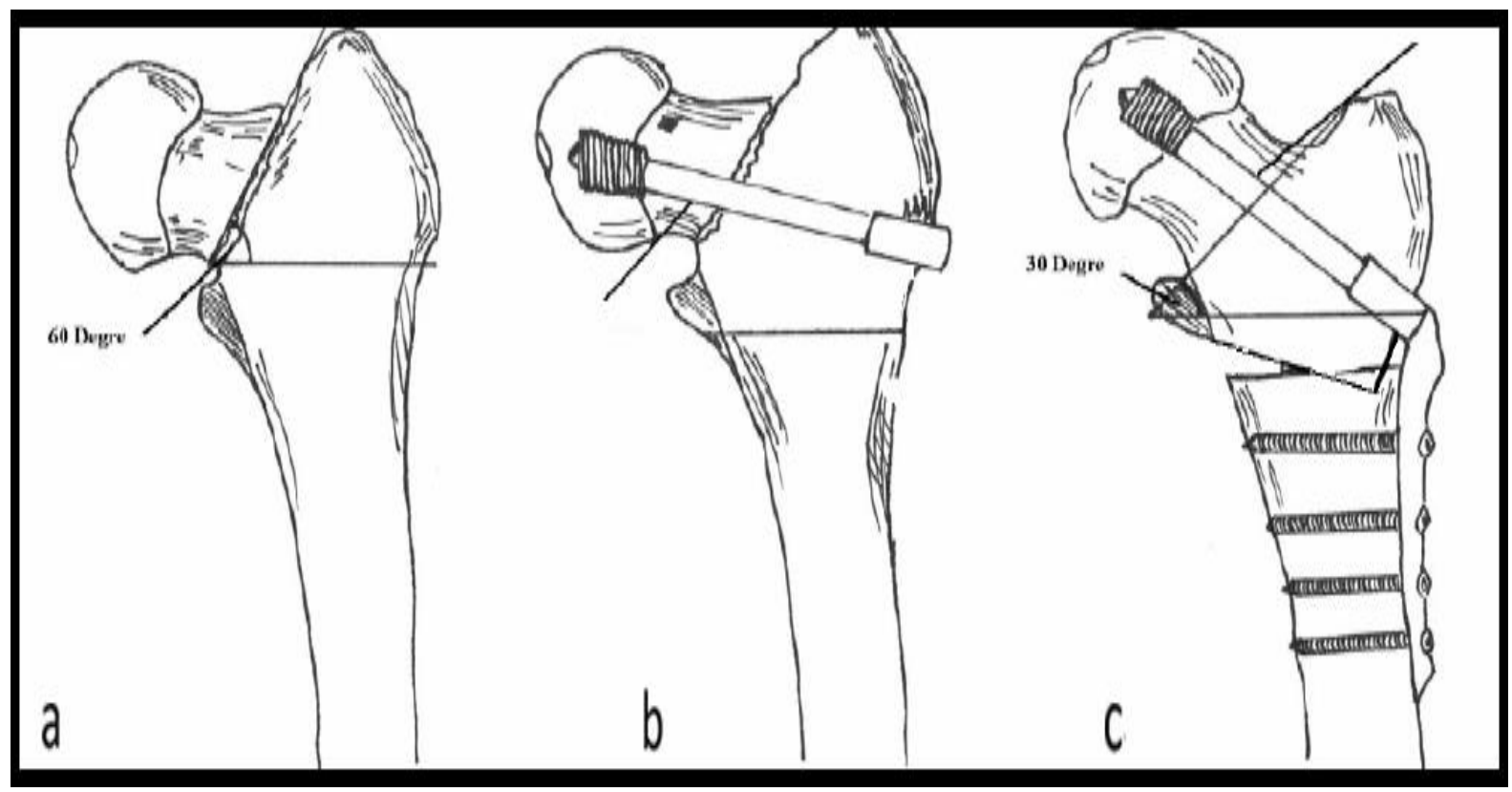

Figure A: Diagram showing stages of valgus osteotomy using DHS. (a): Closed reduction; (b): Insertion of cervical screw and excision of lateral wedge; (c): Final correction after plate fixation.

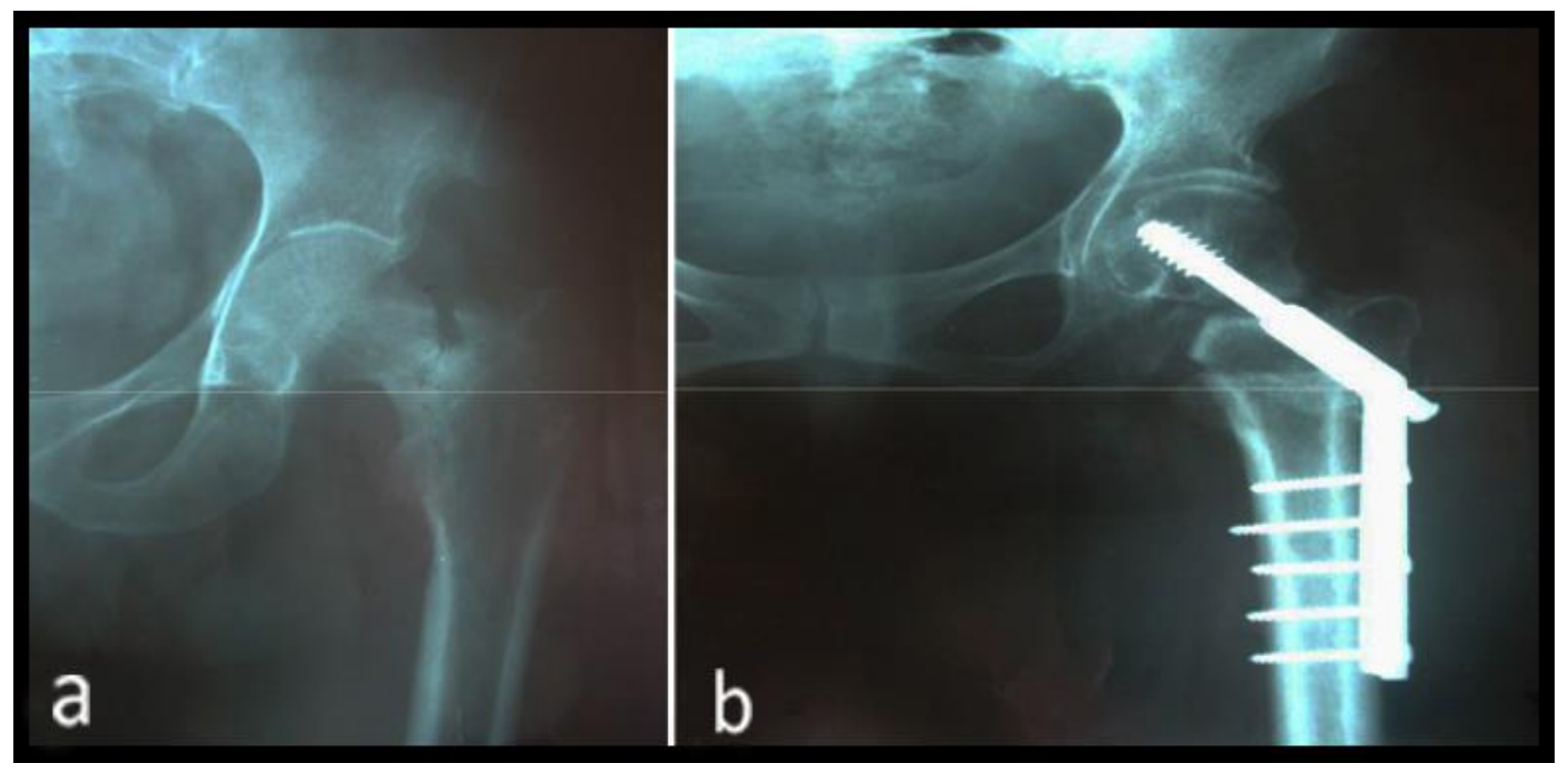

\section{Figure B}

(a): AP radiograph of left hip of a 58 y male shows neglected non union of femoral neck after fracture (b): Postoperative AP radiograph after valgisation osteotomy at $25^{\circ}$ using DHS 


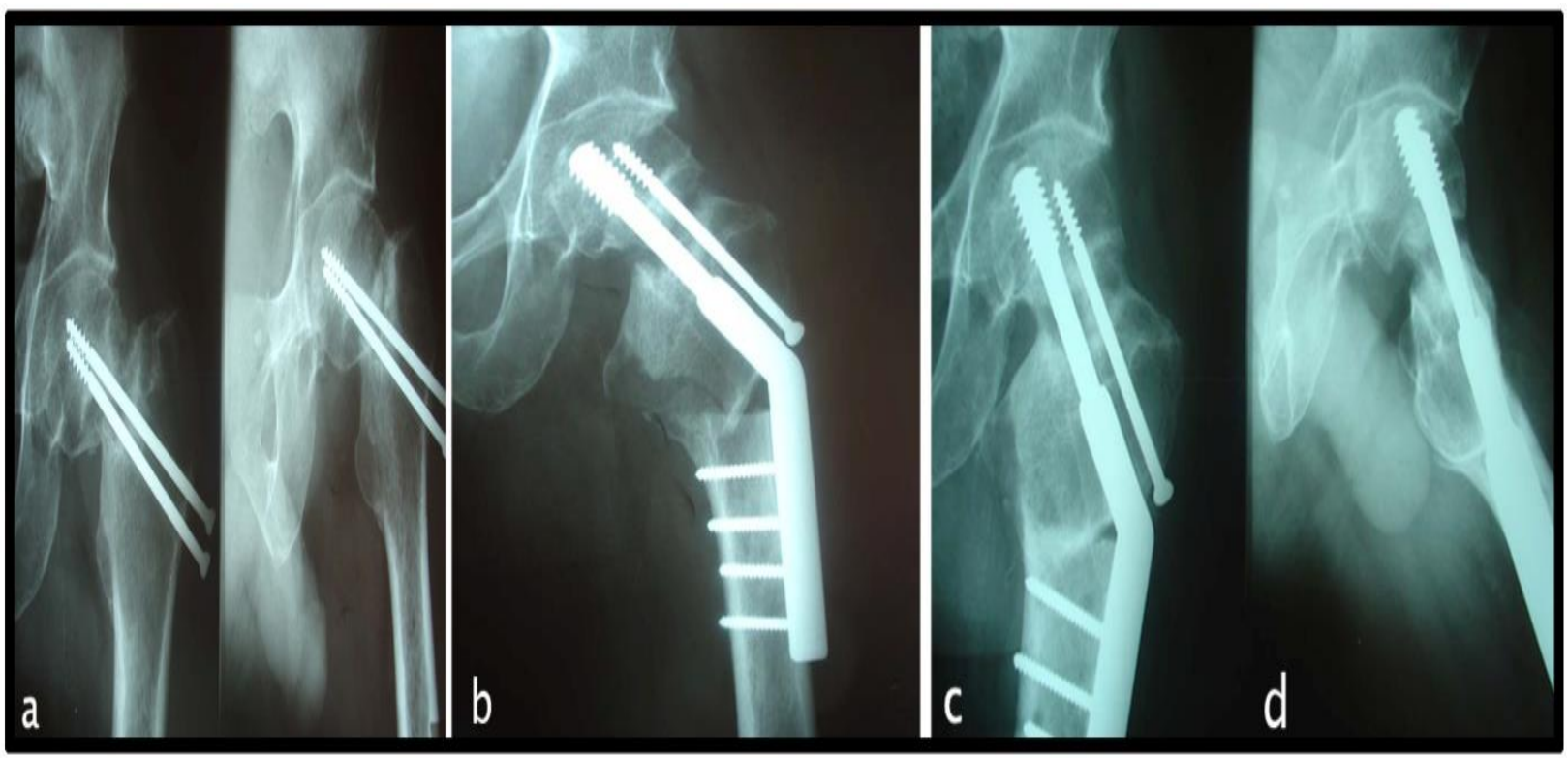

\section{Figure C}

(a): AP radiograph of left hip in a 60y male shows non-union of femoral neck after 6 months of femoral neck fracture G II P II following domestic fall treated by internal fixation with 2 parallel screws (b): Postoperative AP radiograph after valgisation osteotomy at $25^{\circ}$ using DHS (c): AP radiograph and lateral radiograph (d) of the same patient at 8 month followup showing consolidation

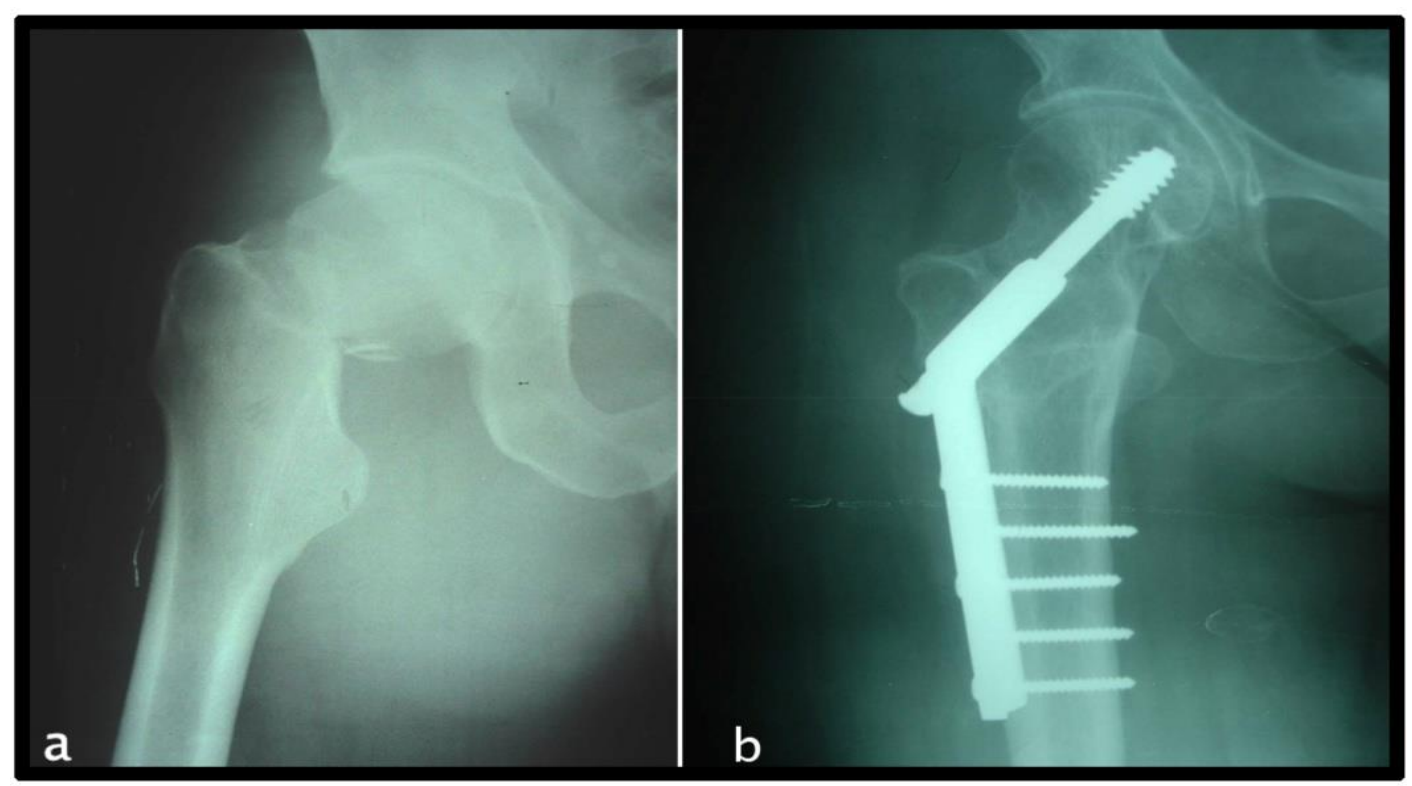

Figure D: (a) AP radiograph of right hip of a 37 y male shows neglected non union of femoral neck after fracture following a motor vehicle accident, (b) radiograph consolidation after 9 months of valgus osteotomy using DHS. 